\title{
双季稻区不同栽培方式对早稻生育期、干物质积累及产量的影响
}

\author{
唐海明 1 逢焕成 ${ }^{2}$ 肖小平 ${ }^{1, *}$ 聂泽民 ${ }^{3} \quad$ 汤文光 $^{1}$ 于天一 ${ }^{2}$ 汪 柯 ${ }^{1}$ \\ 李 强 $^{4}$ 杨光立 $^{1}$
}

${ }^{1}$ 湖南省土壤肥料研究所, 湖南长沙 $410125 ;^{2}$ 中国农业科学院农业资源与农业区划研究所, 北京 $100081 ;{ }^{3}$ 湖南省南县农业局, 湖 南南县 $413200 ;{ }^{4}$ 湖南省南县三仙湖农技站, 湖南南县 413202

摘 要: 为探明洞庭湖平原双季稻区不同栽培方式对早稻生育期、干物质积累及产量的影响, 以常规稻和杂交稻为 材料, 系统比较研究了塑料软盘育种抛栽、手插和机插 3 种栽培方式。结果表明, 与机插相比, 抛栽和手插促进了早 稻生育进程, 全生育期缩短, 抛栽和手插分别缩短 5 8 d 和 $2 \sim 4 \mathrm{~d}$ 。群体根系和地上部干重均表现为抛栽>手插>机插, 差异均达显著水平。成熟期植株根系和穗干物质占总干物质量的比例为抛栽>手插>机插, 茎干物质的比例为手插> 抛栽>机插; 叶干物质比例在分藍期和齐穗期为机插>手插>抛栽, 灌浆期和成熟期为手插>抛栽>机插。分臨期、齐穗 期和灌浆期, 抛栽和手插水稻叶片 SPAD 值均显著高于机插; 成熟期, 各处理间无显著差异。水稻叶面积指数表现为 抛栽>手插>机插。不同栽培方式间水稻产量差异显著, 抛栽最高, 机插最低; 抛栽和手插分别比机插增产 $1203.3 \sim 1346.7 \mathrm{~kg} \mathrm{hm}^{-2}$ 和 776.7 1045.4 $\mathrm{kg} \mathrm{hm}^{-2}$ 。说明不同栽培方式水稻干物质积累和产量有各自特征, 与手插和机 插相比，抛栽处理干物质总量大而且分配合理，有利于改善产量构成因素，增加水稻产量。

关键词: 水稻; 栽培方式; 生育期; 干物质; 产量

\section{Effects of Different Cultivation Methods on Growth Stage, Dry Matter Accu- mulation, and Yield of Early Rice in Double Cropping Rice Field}

TANG Hai-Ming ${ }^{1}$, PANG Huan-Cheng ${ }^{2}$, XIAO Xiao-Ping ${ }^{1, *}$, NIE Ze-Min ${ }^{3}$, TANG Wen-Guang ${ }^{1}$, YU Tian-Yi ${ }^{2}$, WANG $\mathrm{Ke}^{1}$, LI Qiang ${ }^{4}$, and YANG Guang-Li ${ }^{1}$

${ }^{1}$ Hunan Soil and Fertilizer Institute, Changsha 410125, China; ${ }^{2}$ Institute of Agricultural Resources and Regional Planning, Chinese Academy of Agricultural Sciences, Beijing 100081, China; ${ }^{3}$ Nanxian Agricultural Bureau, Nanxian 413200, China; ${ }^{4}$ Sanxianhu Agrotechnical Station, Nanxian 413202, China

\begin{abstract}
To explore the characteristics of growth and development of early rice with different cultivation methods in the double cropping rice system in the Dongting Lake plain, we analyzed the growth stage, dry matter accumulation and distribution, grain yield of early rice with conventional and hybrid rice varieties by using seedling throwing (ST), hand transplanting (HT) and machine transplanting (MT). The results showed that the growth process of ST and HT was earlier and their whole growth period was 5-8 and 2-4 days shortened than that of MT, respectively. For dry matter weight of population, there was significant difference among the three cultivation methods at the main growth stages of early rice, showing on order ST $>$ HT $>$ MT. The dry matter weight ratio of root and panicle to total plant at mature stage and the dry matter weight of stem were both in a trend of $\mathrm{HT}>\mathrm{ST}>\mathrm{MT}$. The dry matter weight ratio of leaf to total plant was MT $>\mathrm{HT}>\mathrm{ST}$ at tillering and heading stages, and HT $>\mathrm{ST}>\mathrm{MT}$ at grain filling and mature stages, respectively. In addition, the leaf SPAD of rice with ST and HT was significantly higher than that with MT at tillering, heading and grain filling stages. But there was no significant difference among ST, HT and MT at mature stage. Meanwhile, the leaf area index for different cultivation methods was ST $>\mathrm{HT}>\mathrm{MT}$ at the main growth stages of early rice. Yield of early rice with different cultivation methods was significantly different, and that of ST was the highest, while that of MT was the lowest. Compared with MT, the yield of ST and HT increased by 1203.3-1346.7 and 776.7-1045.4 $\mathrm{kg} \mathrm{ha}^{-1}$, indicating that the dry matter accumulation and yield of early rice with different cultivation methods have their own characteristics. Com-
\end{abstract}

\footnotetext{
本研究由国家“十二五”公益性行业(农业)科研专项(201103001)和国家“十二五”科技支撑计划项目(2012BAD20B05-01)资助。

*通讯作者(Corresponding author): 肖小平, E-mail: hntfsxxping@163.com, Tel: 0731-84691345

第一作者联系方式: E-mail: tanghaiming66@163.com

Received(收稿日期): 2013-09-03; Accepted(接受日期): 2014-01-12; Published online(网络出版日期): 2014-02-14.

URL: http://www.cnki.net/kcms/detail/11.1809.S.20140214.1020.017.html
} 
pared with HT and MT, ST had significantly higher total dry matter accumulation and its reasonable distribution, and improved yield and yield components.

Keywords: Rice; Cultivation method; Growth stage; Dry matter; Yield

水稻是中国主要粮食作物, 常年种植面积约 3000 万公顷, 占全国谷物种植面积的 $30 \%$, 世界水 稻种植面积的 $27 \%$; 稻谷总产量近 2 亿吨, 占全国 粮食总产的 38\%, 世界稻谷总产的 $35 \%{ }^{[1]}$ 。随着农 业科学技术的进步和农村经济的发展, 水稻栽培方 式由单一的传统手栽发展为手栽、抛种、机插和直 播等多种方式并存的新局面。特别是近年来, 随着 农村劳动人口的战略转移, 轻型、高效的水稻简化 栽培成为社会发展的迫切要求。国内外学者就不同 栽培方式对水稻生育期和产量等方面进行了大量的 研究, 马殿荣等 ${ }^{[2]}$ 研究结果表明, 手插种和抛秧的 产量极显著地高于乳苗抛栽。何瑞银等 ${ }^{[3]}$ 认为, 南方 双季稻区机械插秧方式优于手工插秩, 机械插秩方 式平均增产 $7.53 \%$, 机械直播方式产量平均下降 $6.34 \%$ 。程建平等 ${ }^{[4]}$ 认为, 机械精量穴直播产量比人 工撒播和人工手插处理分别增产 $14.92 \%$ 和 $4.59 \%$ 。 罗锡文等 ${ }^{[5]}$ 试验结果表明, 不同栽植方式的产量差 异不大, 机械栽植与手工栽植方式相比不减产。金 军等 ${ }^{[6]}$ 研究结果表明, 机插稻、手栽稻产量均较高, 抛积稻次之, 直播稻最低。池忠志等 ${ }^{[7]}$ 认为, 机械直 播方式下水稻产量最高, 达 $8974.50 \mathrm{~kg} \mathrm{hm}^{-2}$ 。程建平 等 ${ }^{[8]}$ 认为, 机插的齐穗期比手插晚 $2 \mathrm{~d}$, 在分葟盛期、 孕穗期、抽穗扬花期和成熟期机插的单株地上部分 干重分别比手插提高 $5.98 \% 、 32.36 \%$ 、 $45.93 \%$ 和 $24.52 \%$, 实际增产 $2.73 \%$ 。上述试验由于所处环境条 件、研究方法等的差异, 得出的结果并不一致。目 前, 大多学者主要是在一季稻种植制度条件下, 开 展不同栽培方式对水稻生育期和产量等方面的研 究。塑料软盘育积抛栽、手插和机插是目前洞庭湖 平原双季稻区水稻生产上应用面积最广泛的 3 种栽 培方式。而关于这 3 种栽培方式下水稻的生育期、 干物质积累与分配及产量变化的研究报道较少 ${ }^{[9]}$, 更缺乏在双季稻种植制度下的系统比较研究。本试 验系统比较研究在洞庭湖平原双季稻两熟制条件下, 塑料软盘育积抛栽、手插和机插 3 种栽培方式水稻 的生育期、干物质积累与分配及产量, 以明确其变 化特征, 为科学选用水稻栽培方式提供理论依据。

\section{1 材料与方法}

\section{1 试验地概况}

湖南省益阳市南县三仙湖镇试验地土壤为紫潮 泥; 试验前耕层土壤 $(0 \sim 20 \mathrm{~cm})$ 含有机质 $50.3 \mathrm{~g} \mathrm{~kg}^{-1}$ 、 全氮 $3.25 \mathrm{~g} \mathrm{~kg}^{-1}$ 、全磷 $1.02 \mathrm{~g} \mathrm{~kg}^{-1}$ 、全钾 $22.7 \mathrm{~g} \mathrm{~kg}^{-1}$ 、 碱解氮 $263.0 \mathrm{mg} \mathrm{kg}^{-1}$ 、有效磷 $16.0 \mathrm{mg} \mathrm{kg}^{-1}$ 、速效钾 $104.0 \mathrm{mg} \mathrm{kg}^{-1}, \mathrm{pH} 7.7$ 。该地属亚热带过渡到季风湿 润气候类型, 年降雨量 $1200 \sim 1700 \mathrm{~mm}$, 年平均温度 $16 \sim 18^{\circ} \mathrm{C}$, 年日照时数 $1295.9 \mathrm{~h}$, 无霜期 $260 \sim 310 \mathrm{~d}$ 。

\section{2 试验设计及田间管理}

设 3 个处理, 即抛栽(ST: seedling throwing)、手插 (HT: hand transplanting)和机插(MT: machine transplanting)。每处理 3 次重复, 随机区组排列, 小区面 积 $35.0 \mathrm{~m}^{2}$ (长×宽=7.0 m×5.0 cm)。不同栽培方式间 用塑料薄膜包埂隔离, 保证单独肥水管理。2011 年, 早稻供试品种为湘早籼 45 (常规稻), 3 月 27 日播种, 4 月 21 日移栽; 2012 年, 供试品种为陵两优 211 (杂 交稻), 3 月 24 日播种, 4 月 23 日移栽。抛栽处理采 用塑料软盘育秩, 移栽叶龄 4.4 4.7 叶, 单株平均带 分藍 $1.5 \sim 2.2$ 个, 抛栽密度为 $3.07 \times 10^{5}$ 萖 $\mathrm{hm}^{-2}$, 抛栽 后于田间进行捡匀; 手插处理, 采用塑料软盘育种, 移栽叶龄 4.4 4.7 叶, 栽插行株距 $19.8 \mathrm{~cm} \times 16.5 \mathrm{~cm}$, 二本栽插; 机插处理, 采用机械专用盘育秧, 干种 子落谷量每盘 $110 \mathrm{~g}$, 移栽叶龄 4.0 4.5 叶, 栽插行株 距 $29.7 \mathrm{~cm} \times 12.0 \mathrm{~cm}$ (XL2Z-8, 浙江宁波协力机电制 造有限公司), 栽插后及时查漏补缺, 确保插足基本 苗数; 3 种不同栽插方式的基本苗数常规稻均为 $1.20 \times 10^{6}$ 株 $\mathrm{hm}^{-2}$, 杂交稻均为 $1.05 \times 10^{6}$ 株 $\mathrm{hm}^{-2}$ 。对 常规稻基施氮 $112.5 \mathrm{~kg} \mathrm{hm}^{-2} 、 \mathrm{P}_{2} \mathrm{O}_{5} 90.0 \mathrm{~kg} \mathrm{hm}^{-2} 、 \mathrm{~K}_{2} \mathrm{O}$ $45.0 \mathrm{~kg} \mathrm{hm}^{-2}$, 移栽后 $7 \mathrm{~d}$ 结合施用除草剂追施氮 $34.5 \mathrm{~kg} \mathrm{hm}^{-2}$ 和 $\mathrm{K}_{2} \mathrm{O} 45.0 \mathrm{~kg} \mathrm{hm}^{-2}$; 对杂交稻基施氮 $112.5 \mathrm{~kg} \mathrm{hm}^{-2} 、 \mathrm{P}_{2} \mathrm{O}_{5} 90.0 \mathrm{~kg} \mathrm{hm}^{-2} 、 \mathrm{~K}_{2} \mathrm{O} 45.0 \mathrm{~kg} \mathrm{hm}^{-2}$, 移栽后 $7 \mathrm{~d}$ 结合施用除草剂追施氮 $51.75 \mathrm{~kg} \mathrm{hm}^{-2}$ 和 $\mathrm{K}_{2} \mathrm{O} 45.0 \mathrm{~kg} \mathrm{hm}^{-2}$ 。采用前期淹水、中期烤田和后期 干湿交替的水分管理模式，其他管理措施同常规大 田生产。 


\section{3 测定项目与方法}

1.3.1 生育期记载从播种至成熟, 分别记载各 处理的播种期、移栽期、分蒒期、孕穗期、齐穗期 和成熟期的准确日期。

1.3.2 干物质积累量和叶面积指数测定于早稻 的分菜盛期(移栽后 $25 \mathrm{~d}$ )、齐穗期、灌浆期(灌浆后 10 d)和成熟期 4 个时期, 分别在各小区随机选择 5 穴代表性水稻植株, 每穴以植株为中心, 取长 $25 \mathrm{~cm}$ 、宽 $16 \mathrm{~cm}$ 、深 $20 \mathrm{~cm}$ 的土块, 先用清水冲洗 干净, 注意避免丢失根量, 用滤纸吸干附着水, 然 后将植株按根、茎、叶和穗部位装袋, 于 $105^{\circ} \mathrm{C}$ 杀青 $30 \mathrm{~min}, 80^{\circ} \mathrm{C}$ 烘至恒重, 测定干物质量; 根据公式(单 叶叶面积 $=$ 叶片长 $\times$ 叶片宽 $\times$ 校正系数 $)$ 计算单叶叶面 积, 然后计算植株总叶面积, 求出叶面积指数。

1.3.3 叶片 SPAD值测定 分别于早稻的分菜盛 期、齐穗期、灌浆期和成熟期 4 个时期, 从每小区随 机选择5穴水稻植株, 采用SPAD-502型叶绿素测定 仪测定叶片上部、中部和下部3个点的SPAD值，计算 其平均值, 分薪盛期均测定植株主茎顶部第一展开 叶，齐穗期和灌浆期及成熟期均测定植株主茎剑叶。
1.3.4 产量与产量性状 于成熟期, 从每小区随 机调查 90 穴, 计算单穴平均有效穗数; 从中随机选 取 5 穴考种, 测定每穗粒数、结实率和千粒重等指标, 计算其平均值; 同时，于田间每小区收 $5 \mathrm{~m}^{2}$ ，晒干扬 净，实测干谷产量，折算为公顷产量。

\section{4 数据统计与分析}

使用 Microsoft Excel 2003 处理数据, DPS 软件 进行统计分析。

\section{2 结果与分析}

\section{1 不同栽培方式对水稻生育期的影响}

与机插相比, 抛栽和手插水稻的孕穗、齐穗和 成熟期相应提早，全生育期明显缩短(表 1)。2011 年, 抛栽水稻的孕穗、齐穗和成熟期分别提早 $7 \mathrm{~d} 、 8 \mathrm{~d}$ 和 $8 \mathrm{~d}$, 全生育期缩短 $8 \mathrm{~d}$; 手插水稻的孕穗、齐穗和 成熟期分别提早 $4 d 、 6 d$ 和 $4 d$, 全生育期缩短 $4 d$ 。 2012 年, 抛栽水稻的孕穗、齐穗和成熟期分别提早 $7 \mathrm{~d} 、 5 \mathrm{~d}$ 和 $5 \mathrm{~d}$ ，全生育期缩短 $5 \mathrm{~d}$; 手插水稻的孕穗、 齐穗和成熟期分别提早 $4 \mathrm{~d} 、 2 \mathrm{~d}$ 和 $2 \mathrm{~d}$ ，全生育期缩 短 $2 \mathrm{~d}$ 。

表 1 不同栽培方式对水稻生育期的影响

Table 1 Growth stage of rice under different cultivation methods

\begin{tabular}{ccccccccc}
\hline $\begin{array}{c}\text { 年份 } \\
\text { Year }\end{array}$ & $\begin{array}{c}\text { 处理 } \\
\text { Treatment }\end{array}$ & $\begin{array}{c}\text { 播种期 } \\
\mathrm{SS} \mathrm{(M/D)}\end{array}$ & $\begin{array}{c}\text { 移栽期 } \\
\mathrm{TD}(\mathrm{M} / \mathrm{D})\end{array}$ & $\begin{array}{c}\text { 分藍盛期 } \\
\mathrm{TS}(\mathrm{M} / \mathrm{D})\end{array}$ & $\begin{array}{c}\text { 孕穗期 } \\
\mathrm{BS}(\mathrm{M} / \mathrm{D})\end{array}$ & $\begin{array}{c}\text { 齐穗期 } \\
\text { HS (M/D) }\end{array}$ & $\begin{array}{c}\text { 成熟期 } \\
\text { MS (M/D) }\end{array}$ & $\begin{array}{c}\text { 生育期 } \\
\text { Whole growth stage (d) }\end{array}$ \\
\hline 2011 & 抛栽 ST & $3 / 27$ & $4 / 21$ & $5 / 27$ & $6 / 6$ & $6 / 12$ & $7 / 10$ & 104 \\
& 手插 HT & $3 / 27$ & $4 / 21$ & $6 / 1$ & $6 / 9$ & $6 / 14$ & $7 / 14$ & 108 \\
& 机插 MT & $3 / 27$ & $4 / 21$ & $6 / 4$ & $6 / 13$ & $6 / 20$ & $7 / 18$ & 112 \\
& 抛栽 ST & $3 / 24$ & $4 / 23$ & $6 / 1$ & $6 / 8$ & $6 / 17$ & $7 / 10$ & 108 \\
& 手插 HT & $3 / 24$ & $4 / 23$ & $6 / 3$ & $6 / 11$ & $6 / 20$ & $7 / 13$ & 111 \\
& 机插 MT & $3 / 24$ & $4 / 23$ & $6 / 5$ & $6 / 15$ & $6 / 22$ & $7 / 15$ & 113 \\
\hline
\end{tabular}

ST：抛栽; HT：手插; MT：机插。SS：播种期; TD：移栽期; TS：分轹盛期; BS：孕穗期; HS：齐穗期; MS：成熟期; M/D：月/日。

ST: seedling throwing; HT: hand transplanting; MT: machine transplanting. SS: sowing stage; TD: transplanting date; TS: tillering stage; BS: booting stage; HS: heading stage; MS: maturity stage. M/D: month/day.

\section{2 不同栽培方式对水稻叶片 SPAD 的影响}

由图 1 可知, 在早稻各生育期, 各处理水稻叶 片 SPAD 值呈先增后减的趋势, 于齐穗期达到最高 值。分藍期抛栽水稻显著高于其他处理, 分别比手 插和机插水稻增加 $18.21 \% 、 18.53 \%$ (2011 年)和 $7.38 \% 、 11.24 \%$ (2012 年); 齐穗期、灌浆期均以抛栽 和手插水稻为最高, 均显著高于机插水稻; 成熟期 各处理间 SPAD 值无明显差异。

\section{3 不同栽培方式对水稻叶面积指数的影响}

图 2 显示, 各处理早稻叶面积指数(LAI)呈抛物 线变化趋势。分䅦期至齐穗期, 抛栽和手插早稻的
LAI 均显著高于机插，且均在齐穗期达最高，分别 比机插增加 2.02、1.75 (2011 年)和 2.12、1.83 (2012 年)。早稻各生育期 LAI 表现为抛栽>手插>机插, 即 采用抛栽和人工移栽具有更大的叶面积指数。

2.4 不同栽培方式对水稻干物质生产特征的影响

2.4.1 不同栽培方式水稻主要生育期群体千物重 由表 2 可知, 群体根系干重为抛栽>手插>机插; 于灌浆期达最大值, 抛栽水稻分别比手插、机插水 稻平均高 $17.14 \%$ 和 $53.49 \%$, 手插水稻比机插水稻平 均高 $29.94 \%$ 。群体地上部干重于成熟期达最大值, 抛栽水稻分别比手插、机插水稻平均高 $4.21 \%$ 和 

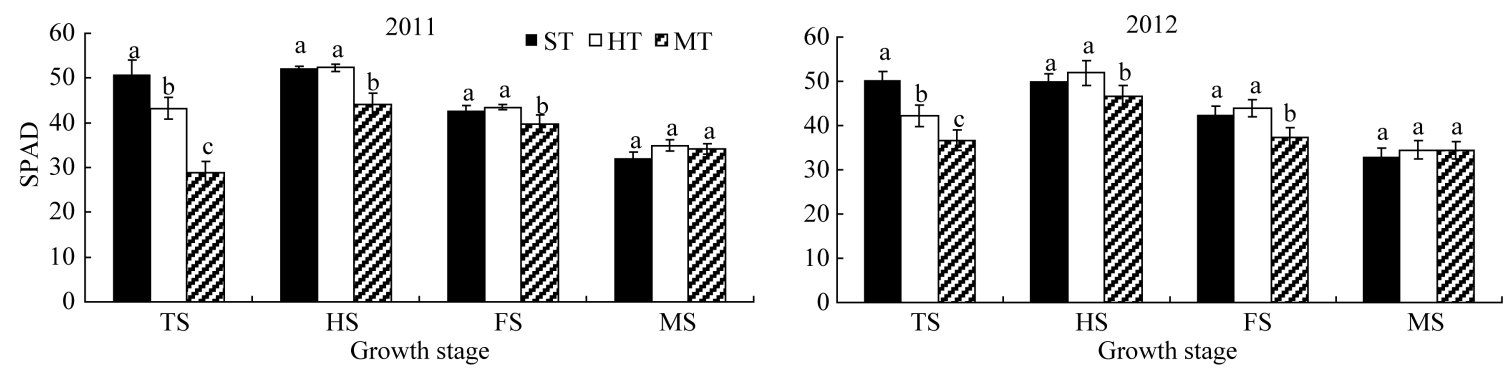

图 1 不同栽培方式对水稻叶片 SPAD 的影响

Fig. 1 Effects of different cultivation methods on SPAD of rice leaf

TS: 分萎盛期; HS: 齐穗期; FS: 灌浆期; MS: 成熟期。图中不同字母表示不同处理之间差异显著。

TS: tillering stage; HS: heading stage; FS: filling stage; MS: maturity stage. Band represented by different letters are significantly different between different treatments.
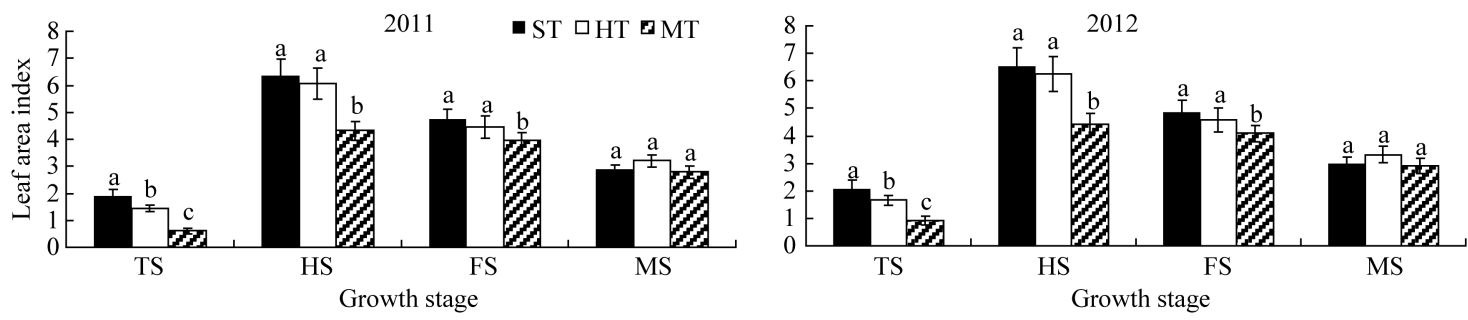

图 2 不同栽培方式对水稻叶面积指数的影响

Fig. 2 Effects of different cultivation methods on leaf area index of rice

TS: 分蒒盛期; HS: 齐穗期; FS: 灌浆期; MS: 成熟期。图中不同字母表示不同处理之间差异显著。

TS: tillering stage; HS: heading stage; FS: filling stage; MS: maturity stage. Band represented by different letters are significantly different between different treatments.

$17.35 \%$, 手插水稻比机插水稻平均高 $12.57 \%$ 。在早 稻主要生育期, 水稻地上部分的茎、叶、穗均以抛栽 水稻最高, 手插水稻次之, 机插水稻最低; 抛栽和手 插水稻均明显高于机插水稻，但两者间无显著差异 (表 3)。

2.4 .2 水稻根、茎、叶、穗各部分占植株总干物质 重的比例及其变化 根系干重占总干物质重的比 例表现为抛栽>手插>机插; 茎的比例为手插>抛栽> 机插; 叶比例在分菜期和齐穗期均以机插水稻最大,
手插次之，抛栽最小，灌浆期和成熟期的手插水稻 最大，机插最小; 穗干重占植株总干物质重的比例 为抛栽>手插>机插。根和叶的比例均在分䔉期最大, 随着生育进程不断降低，至成熟期降至最低，根的 比例从 $16.43 \% \sim 23.48 \%$ 降到 $3.88 \% \sim 4.99 \%$, 叶的比 例从 $26.45 \% \sim 34.34 \%$ 降到 $8.66 \% \sim 11.01 \%$ 。茎的比例 于齐穗期达最大值, 之后呈下降趋势。穗的比例随 生育进程不断增大，到成熟期占总干物质量的 $55.38 \% \sim 64.97 \%$ (表 4)。

表 2 不同栽培方式水稻主要生育期群体干物重

Table 2 Dry matter weight of population at main growth stage of rice with different cultivation methods $\left(\mathrm{kg} \mathrm{hm}^{-2}\right)$

\begin{tabular}{|c|c|c|c|c|c|c|c|c|c|}
\hline \multirow{2}{*}{$\begin{array}{l}\text { 年份 } \\
\text { Year }\end{array}$} & \multirow{2}{*}{$\begin{array}{c}\text { 处理 } \\
\text { Treatment }\end{array}$} & \multicolumn{4}{|c|}{ 群体根系干重 Root dry weight of population } & \multicolumn{4}{|c|}{ 群体地上部总干重 Shoot dry weight of population } \\
\hline & & $\begin{array}{c}\text { 分䒩盛期 } \\
\mathrm{TS}\end{array}$ & $\begin{array}{c}\text { 齐穗期 } \\
\text { HS }\end{array}$ & $\begin{array}{c}\text { 灌浆期 } \\
\text { FS }\end{array}$ & $\begin{array}{c}\text { 成熟期 } \\
\text { MS }\end{array}$ & $\begin{array}{c}\text { 分藮盛期 } \\
\text { TS }\end{array}$ & $\begin{array}{c}\text { 齐穗期 } \\
\text { HS }\end{array}$ & $\begin{array}{c}\text { 灌浆期 } \\
\text { FS }\end{array}$ & $\begin{array}{c}\text { 成熟期 } \\
\text { MS }\end{array}$ \\
\hline \multirow[t]{3}{*}{2011} & 抛秧 ST & $654.9 \mathrm{a}$ & $680.5 \mathrm{a}$ & $1012.5 \mathrm{a}$ & $571.2 \mathrm{a}$ & $2187.5 \mathrm{a}$ & $6904.9 \mathrm{a}$ & $10533.0 \mathrm{a}$ & $10519.7 \mathrm{a}$ \\
\hline & 手插 HT & $460.8 \mathrm{~b}$ & $605.9 \mathrm{a}$ & $814.3 \mathrm{a}$ & $498.6 \mathrm{a}$ & $1875.9 \mathrm{a}$ & $6133.4 \mathrm{a}$ & $9685.0 \mathrm{a}$ & $9856.6 \mathrm{a}$ \\
\hline & 机插 MT & $255.7 \mathrm{c}$ & $441.1 \mathrm{~b}$ & $551.7 \mathrm{~b}$ & $421.5 \mathrm{~b}$ & $1139.8 \mathrm{~b}$ & $5424.7 \mathrm{~b}$ & $8455.5 \mathrm{~b}$ & $8654.1 \mathrm{~b}$ \\
\hline \multirow[t]{3}{*}{2012} & 抛秧 ST & $765.3 \mathrm{a}$ & $735.6 \mathrm{a}$ & $1027.9 \mathrm{a}$ & $645.7 \mathrm{a}$ & $2494.0 \mathrm{a}$ & $9128.9 \mathrm{a}$ & $10705.7 \mathrm{a}$ & $12881.0 \mathrm{a}$ \\
\hline & 手插 HT & $566.0 \mathrm{~b}$ & $665.9 \mathrm{a}$ & $934.9 \mathrm{a}$ & $573.2 \mathrm{a}$ & $2100.7 \mathrm{a}$ & $7893.6 \mathrm{a}$ & $10288.8 \mathrm{a}$ & $12665.4 \mathrm{a}$ \\
\hline & 机插 MT & $330.6 \mathrm{c}$ & $542.3 \mathrm{~b}$ & $832.6 \mathrm{~b}$ & $458.9 \mathrm{~b}$ & $1693.0 \mathrm{~b}$ & $6827.7 \mathrm{~b}$ & $9097.1 \mathrm{~b}$ & $11384.2 \mathrm{~b}$ \\
\hline
\end{tabular}

ST: 抛栽; HT: 手插; MT: 机插. TS: 分藍盛期; HS：齐穗期; FS: 灌浆期; MS: 成熟期。同列内小写字母不同表示显著差异 $(P<0.05)$ 。

ST: seedling throwing; HT: hand transplanting; MT: machine transplanting. TS: tillering stage; HS: heading stage; FS: filling stage; MS: maturity stage. Values followed by different small letters within a column are significantly different at $P<0.05$. 
表 3 不同栽培方式水稻主要生育期地上部茎、叶和穗群体干物重

Table 3 Stem, leaf and panicle dry weight of population at main growth stage of rice with different cultivation methods $\left(\mathrm{kg}_{\mathrm{g}} \mathrm{h}^{-2}\right)$

\begin{tabular}{|c|c|c|c|c|c|c|c|c|c|c|c|c|}
\hline \multirow{2}{*}{$\begin{array}{l}\text { 年份 } \\
\text { Year }\end{array}$} & \multirow{2}{*}{$\begin{array}{c}\text { 处理 } \\
\text { Treatment }\end{array}$} & \multicolumn{4}{|c|}{ 茎 Stem } & \multicolumn{4}{|c|}{ 叶 Leaf } & \multicolumn{3}{|c|}{ 穗 Panicle } \\
\hline & & $\begin{array}{c}\text { 分菜盛期 } \\
\text { TS }\end{array}$ & $\begin{array}{c}\text { 齐穗期 } \\
\text { HS }\end{array}$ & $\begin{array}{c}\text { 灌浆期 } \\
\text { FS } \\
\end{array}$ & $\begin{array}{c}\text { 成熟期 } \\
\text { MS }\end{array}$ & $\begin{array}{c}\text { 分藍盛期 } \\
\text { TS }\end{array}$ & $\begin{array}{c}\text { 齐穗期 } \\
\text { HS }\end{array}$ & $\begin{array}{c}\text { 灌浆期 } \\
\text { FS } \\
\end{array}$ & $\begin{array}{c}\text { 成熟期 } \\
\text { MS }\end{array}$ & $\begin{array}{c}\text { 齐穗期 } \\
\text { HS } \\
\end{array}$ & $\begin{array}{c}\text { 灌浆期 } \\
\text { FS } \\
\end{array}$ & $\begin{array}{c}\text { 成熟期 } \\
\text { MS }\end{array}$ \\
\hline \multirow[t]{3}{*}{2011} & 抛秧 ST & $1427.6 \mathrm{a}$ & $4093.1 \mathrm{a}$ & $6335.7 \mathrm{a}$ & $3008.0 \mathrm{a}$ & 759.9 a & 2096.6 a & $2691.2 \mathrm{a}$ & $1171.9 \mathrm{a}$ & $715.2 \mathrm{a}$ & $1506.0 \mathrm{a}$ & $6339.8 \mathrm{a}$ \\
\hline & 手插 HT & $1223.5 \mathrm{a}$ & $3592.4 \mathrm{a}$ & $5866.8 \mathrm{a}$ & $2872.1 \mathrm{a}$ & $652.4 \mathrm{a}$ & $1904.5 \mathrm{a}$ & $2336.7 \mathrm{a}$ & $1140.3 \mathrm{a}$ & $636.5 \mathrm{a}$ & $1481.5 \mathrm{a}$ & $5844.3 \mathrm{a}$ \\
\hline & 机插 MT & $660.7 \mathrm{~b}$ & $3144.1 \mathrm{~b}$ & $5219.6 \mathrm{~b}$ & $2570.0 \mathrm{~b}$ & $479.2 \mathrm{~b}$ & $1720.5 \mathrm{~b}$ & 2099.8 b & $916.9 \mathrm{~b}$ & $560.1 \mathrm{~b}$ & $1136.1 \mathrm{~b}$ & $5167.1 \mathrm{~b}$ \\
\hline \multirow[t]{3}{*}{2012} & 抛秧 ST & $1632.0 \mathrm{a}$ & 6069.8 a & $6315.3 \mathrm{a}$ & $3023.3 \mathrm{a}$ & $862.1 \mathrm{a}$ & $2099.7 \mathrm{a}$ & $2733.1 \mathrm{a}$ & $1262.9 \mathrm{a}$ & $959.4 \mathrm{a}$ & $1657.2 \mathrm{a}$ & $8594.8 \mathrm{a}$ \\
\hline & 手插 HT & $1346.1 \mathrm{a}$ & $5472.5 \mathrm{a}$ & $6076.2 \mathrm{a}$ & $2954.8 \mathrm{a}$ & $754.5 \mathrm{a}$ & $2022.3 \mathrm{a}$ & $2577.8 \mathrm{a}$ & $1200.5 \mathrm{a}$ & $898.9 \mathrm{a}$ & $1634.8 \mathrm{a}$ & $8510.0 \mathrm{a}$ \\
\hline & 机插 MT & $1060.2 \mathrm{~b}$ & $4436.6 \mathrm{~b}$ & $5356.3 \mathrm{~b}$ & $2664.6 \mathrm{~b}$ & $632.8 \mathrm{~b}$ & $1735.0 \mathrm{~b}$ & $2327.4 \mathrm{~b}$ & $1025.6 \mathrm{~b}$ & $656.1 \mathrm{~b}$ & $1413.3 \mathrm{~b}$ & $7694.1 \mathrm{~b}$ \\
\hline
\end{tabular}

ST: 抛栽; HT: 手插; MT: 机插. TS: 分樫盛期; HS: 齐穗期; FS: 灌浆期; MS: 成熟期。同列内小写字母不同表示显著差异 $(P<0.05)$ 。

ST: seedling throwing; HT: hand transplanting; MT: machine transplanting. TS: tillering stage; HS: heading stage; FS: filling stage; MS: maturity stage. Values followed by different small letters within a column are significantly different at $P<0.05$.

表 4 不同栽培方式水稻根、茎、叶、穗各部分占植株总干物质重的比例及其变化

Table 4 Dry weight ratio of root, stem, leaf, panicle to total plant and its variation at main growth stages of rice with different cultivation methods $(\%)$

\begin{tabular}{|c|c|c|c|c|c|c|c|c|c|c|c|c|c|c|c|c|}
\hline \multirow{3}{*}{$\begin{array}{l}\text { 年份 } \\
\text { Year }\end{array}$} & \multirow{3}{*}{$\begin{array}{c}\text { 处理 } \\
\text { Treatment }\end{array}$} & \multicolumn{4}{|c|}{ 根比例 Ratio of root } & \multicolumn{4}{|c|}{ 茎比例 Ratio of steam } & \multicolumn{4}{|c|}{ 叶比例 Ratio of leaf } & \multicolumn{3}{|c|}{ 穗比例 Ratio of panicle } \\
\hline & & $\begin{array}{l}\text { 分藍 } \\
\text { 成期 }\end{array}$ & 齐穗期 & 灌浆期 & 成熟期 & 分葟 & 齐穗期 & 灌浆期 & 成熟期 & 分蒒 & 齐穗期 & 灌浆期 & 成熟期 & 齐穗期 & 灌浆期 & 成熟期 \\
\hline & & $\begin{array}{c}\text { 笽期 } \\
\text { TS }\end{array}$ & HS & FS & MS & $\begin{array}{c}\text { 笽期 } \\
\text { TS }\end{array}$ & HS & FS & MS & $\begin{array}{c}\text { 笽供 } \\
\text { TS }\end{array}$ & HS & FS & MS & HS & FS & MS \\
\hline \multirow[t]{3}{*}{2011} & 抛秧 ST & 23.04 & 8.99 & 8.77 & 4.99 & 50.22 & 55.88 & 53.60 & 27.74 & 27.64 & 26.73 & 23.30 & 10.24 & 9.55 & 14.11 & 56.93 \\
\hline & 手插 HT & 19.72 & 8.97 & 7.76 & 4.81 & 52.36 & 57.95 & 53.96 & 28.32 & 28.26 & 27.92 & 23.31 & 11.01 & 9.45 & 13.04 & 56.44 \\
\hline & 机插 MT & 18.32 & 7.52 & 6.12 & 4.64 & 47.34 & 54.88 & 53.31 & 26.27 & 34.34 & 29.33 & 22.26 & 10.10 & 9.43 & 12.61 & 55.38 \\
\hline \multirow[t]{3}{*}{2012} & 抛秧 ST & 23.48 & 7.78 & 8.76 & 4.77 & 50.48 & 60.20 & 53.94 & 22.32 & 26.45 & 21.28 & 23.29 & 9.07 & 10.50 & 14.57 & 64.97 \\
\hline & 手插 HT & 21.23 & 7.46 & 8.33 & 4.33 & 52.39 & 61.53 & 54.14 & 22.35 & 28.29 & 23.54 & 23.44 & 9.34 & 9.73 & 14.23 & 64.28 \\
\hline & 机插 MT & 16.34 & 7.36 & 8.39 & 3.88 & 50.07 & 58.09 & 53.82 & 22.50 & 31.27 & 23.63 & 22.97 & 8.66 & 8.90 & 14.12 & 63.54 \\
\hline
\end{tabular}

ST: 抛栽; HT: 手插; MT: 机插。 TS: 分葟盛期; HS: 齐穗期; FS: 灌浆期; MS: 成熟期。

ST: seedling throwing; HT: hand transplanting; MT: machine transplanting. TS: tillering stage; HS: heading stage; FS: filling stage; MS: maturity stage.

\section{5 不同栽培方式对水稻产量及其构成因素的 影响}

由表 5 可知, 有效穗以抛栽水稻最多, 手插水 稻最少，不同栽培方式间差异达显著水平; 每穗 粒数以手插水稻最高, 机插水稻最少, 不同栽培
方式间差异达显著水平; 抛栽和手插水稻结实率 无显著差异, 手插水稻的结实率显著高于机插水 稻; 各处理的千粒重无显著差异。抛栽和手插水稻 产量均显著高于机插水稻，平均分别增产 $20.33 \%$ 和 $14.50 \%$ 。

表 5 不同栽培方式水稻的产量及其构成因素

Table 5 Effects of different cultivation methods on yield and yield components of rice

\begin{tabular}{|c|c|c|c|c|c|c|}
\hline 年份 & 处理 & 有效穗 & 穗粒数 & 结实率 & 千粒重 & 产量 \\
\hline Year & Treatment & Effective panicle $\left(\times 10^{4} \mathrm{hm}^{-2}\right)$ & Spikelets per panicle & Seed setting rate $(\%)$ & 1000 -grain weight $(\mathrm{g})$ & Yield $\left(\mathrm{kg} \mathrm{hm}^{-2}\right)$ \\
\hline \multirow[t]{3}{*}{2011} & 抛栽 ST & $405.30 \mathrm{a}$ & $100.01 \mathrm{ab}$ & $88.10 \mathrm{ab}$ & $23.21 \mathrm{a}$ & $7358.70 \mathrm{a}$ \\
\hline & 手插 HT & $320.73 \mathrm{c}$ & $108.21 \mathrm{a}$ & $90.31 \mathrm{a}$ & $23.15 \mathrm{a}$ & $6932.10 \mathrm{a}$ \\
\hline & 机插 MT & $377.41 \mathrm{~b}$ & $94.13 \mathrm{~b}$ & $84.01 \mathrm{~b}$ & $23.13 \mathrm{a}$ & $6155.40 \mathrm{~b}$ \\
\hline \multirow[t]{3}{*}{2012} & 抛栽 ST & $342.46 \mathrm{a}$ & $124.87 \mathrm{ab}$ & $79.27 \mathrm{ab}$ & $25.63 \mathrm{a}$ & $7728.75 \mathrm{a}$ \\
\hline & 手插 HT & $301.93 \mathrm{c}$ & $129.89 \mathrm{a}$ & $83.98 \mathrm{a}$ & $24.52 \mathrm{a}$ & $7427.40 \mathrm{a}$ \\
\hline & 机插 MT & $320.46 \mathrm{~b}$ & $111.71 \mathrm{~b}$ & $76.31 \mathrm{~b}$ & $24.45 \mathrm{a}$ & $6382.05 \mathrm{~b}$ \\
\hline
\end{tabular}

ST: 抛栽; HT: 手插; MT: 机插。同列内小写字母不同表示显著差异 $(P<0.05)$ 。

ST: seedling throwing; HT: hand transplanting; MT: machine transplanting. Values followed by different small letters within a column are significantly different at $P<0.05$. 


\section{3 讨论}

3.1 不同栽培方式对水稻生育期及产量的影响 有研究表明, 在正常抽穗成熟的条件下, 水稻 产量一般随生育期的延长呈增加的趋势 ${ }^{[10]}$ 。生育期 作为水稻品种的遗传属性, 主要由自身的感温性、感 光性、基本营养生长习性决定 ${ }^{[11]}$ ，也受播栽期 ${ }^{[12-13]}$ 、 栽培方式 ${ }^{[2,4]}$ 及生态环境条件 ${ }^{[14-15]}$ 等因素的影响。不 同栽培方式的水稻, 播栽期不同, 所处的温光等环 境条件各异, 且各栽培方式水稻又有自身的生长发 育特征, 因此其生育期长短及生育进程呈规律性变 化。本研究表明, 与抛栽相比, 手插和机插水稻的各 生育进程均延迟, 全生育期延长, 手插水稻延长3 $4 \mathrm{~d}$, 机插水稻延长 5 8 d。其主要原因可能是机械专 用盘育成的秧苗素质一般, 移栽入土深, 分葟节位 升高, 不利于秩苗返青和早发; 手插积苗入土较深, 不利于积苗返青, 推迟早稻分葟, 影响了早稻的生 育进程; 而抛栽水稻, 采用塑料软盘育苗, 其积苗 素质较好, 在抛栽时, 积苗入土浅, 分藍节位降低, 有利于积苗返青和促进早发, 对移栽大田后的生育 进程无明显不利影响。不同栽培方式水稻由于生育 期长短不同, 其产量也有差异。在洞庭湖平原双季 稻区，保证早稻产量的前提下，还需综合考虑早、晚 稻的衔接搭配, 若早稻生育期过长, 影响晚稻的移 栽、生长发育, 进而影响晚稻的安全生产。

在种植一季稻的条件下, 前人开展了不同栽培 方式对水稻产量影响的研究, 结果并不一致。马殿 荣等 ${ }^{[2]}$ 研究结果显示, 手栽产量最高, 抛秧次之, 直 播最低。程建平等 ${ }^{[4]}$ 研究认为机穴直播产量最高, 手 栽次之, 人工撒直播最低。池忠志等 ${ }^{[7]}$ 研究表明机直 播产量最高, 机插次之, 手栽最低。本研究表明, 不 同类型品种水稻产量均以抛栽最高, 手插次之, 机 插最低; 与机插相比，抛栽一般增产1203.3 1346.7 $\mathrm{kg} \mathrm{hm}{ }^{-2}$, 手插增产776.7 1045.4 kg hm${ }^{-2}$, 不同年份 间增产率平均分别为 $19.55 \%$ 、 $12.62 \%$ 和 $21.10 \%$ 、 $16.38 \%$ 。这可能是抛栽水稻, 采用塑料软盘育苗, 其 积苗素质较好, 有利于积苗返青和促进早发, 提高 分蒒率和成穗率, 增加了单位面积的有效穗数。而 机插水稻积苗素质较差, 影响栽插质量和大田生长, 移栽后积苗返青慢, 返青期较抛栽长2 3 d, 全生育 期延长; 且机插时秧苗入土较深, 分蒒高峰滞后, 不利于保藍足穗和壮秆促大穗。前人的研究表明机 插水稻增产或者不减产, 是因为在种植一季稻的条
件下，有利于安排全年作物茬口，能保证机插水稻 全生育期, 可充分利用后期的温光条件, 保证水稻

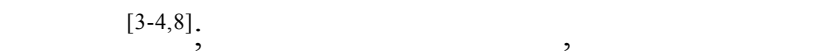
季稻两熟制条件下所开展，由于机插早稻生育期延 长, 为保证晚稻生产正常开展, 需及时收获早稻, 影响了早稻后期的灌浆, 降低了结实率和千粒重, 从而降低了水稻产量, 这与罗锡文等 ${ }^{[5]}$ 的研究结果 一致。农业机械化是个复杂的系统工程, 在实施过 程中会遇到许多具体问题。关于水稻机械移栽，在 具体操作过程中需综合考虑选择适宜的水稻品种和 播种期，严格控制好秧龄，保证积苗素质，以提高 移栽质量; 同时, 对农机与农艺配套措施还有待进 一步研究。

籽粒产量主要来源于光合产物, 叶片是进行光 合作用、制造光合产物的主要器官, 合理的叶面积 及其动态是水稻高产的重要保证。吴文革等 ${ }^{[16]}$ 研究 认为, 超级杂交中籼稻中后期的叶面积较对照明显 提高。李杰等 ${ }^{[17]}$ 在稻一麦两熟制条件下的研究表明, 拔节期后手栽稻的叶面积极显著高于机插稻，机插 稻又极显著高于直播稻。在本研究中, 采用抛栽和 人工移栽水稻具有更大的叶面积指数, 均明显高于 机插水稻; 抛栽和人工移栽水稻的叶面积指数大且 衰减速度慢，为保证其后期物质生产能力奠定了生 理基础。

\section{2 不同栽培方式对水稻的干物质生产、分配的} 影响

水稻产量是植株个体群体干物质积累、分配、 运输与转化的结果。不同栽培方式水稻由于植株个 体和群体生长环境不同，对养分和温光等资源的利 用不同，必然会对其生长产生一定的影响。马殿荣 等 ${ }^{[18]}$ 研究认为, 不同栽培方式水稻产量与干物质积 累总量呈极显著正相关。单茎干物重和群体干物重 是水稻个体生长强弱和群体质量高低的主要标志, 充分发挥个体的生长潜力在一定程度上往往更利于 群体物质生产能力的改善。本研究表明，采用机插 专用育秧盘所培育的积苗素质较塑料软盘所培育的 积苗略差(株高矮、叶龄小、单株绿叶数少、茎基宽 小、总根数和白根数少), 栽插时入土较深, 不利于 水稻返青，造成机插水稻个体与群体发展不协调， 群体茎䔉数多而质量弱。不同栽培方式间群体根系 和地上部干重变化一致, 均表现为抛栽 $>$ 手插 $>$ 机插, 差异均达显著水平, 并随生育进程差异越来越大。 抛栽和手插水稻干物质积累量均显著高于机插水稻, 
因此认为, 较高的物质生产能力, 是抛栽和手插水 稻产量较机插水稻高的物质基础。

水稻籽粒的灌浆物质一部分来自抽穗后的光合 产物, 另外一部分来自叶茎鞘贬藏物质的再分配。 前人研究表明, 高产水稻一般前中期叶茎鞘等器官 䛎藏的光合产物多, 后期光合产物分配于穗部的比 例大, 且叶茎鞘的䛎藏物质能较多地运转到穗部 ${ }^{[19]}$ 。 本研究结果表明, 在水稻成熟期, 植株穗干物质占 总干物质量的比例抛栽、手插、机插依次降低, 茎 干物质的比例手插、抛栽、机插依次降低; 叶干物 质比例在灌浆期和成熟期, 表现为手插 $>$ 抛栽 $>$ 机 插。说明与机插稻相比, 抛栽、手插水稻有着良好 的光合和群体支撑系统, 干物质在各器官间的分配 合理，成熟期穗部物质比例大。

本文仅针对洞庭湖平原双季稻区不同栽培方式 对早稻生育期、干物质积累和分配及产量的影响开 展了初步研究, 不同栽培方式对晚稻的影响还需进 一步探讨。

\section{4 结论}

与机插水稻相比, 抛栽和手插水稻的生育进程 提前, 生育期缩短; 从生育期来看, 抛栽和手插水 稻全生育期适宜, 有利于晚稻农事生产安排, 保证 双季稻的周年茬口衔接。物质生产方面, 与机插水 稻相比, 拋栽和手插水稻个体群体生长协调, 移栽 至大田后水稻植株物质生产能力强, 干物质积累多, 而且在各器官间的分配合理。根系干重占总干物质 重的比例均以抛栽水稻最大; 茎的比例均为手插> 抛栽>机插。叶的比例在分臨盛期和齐穗期均以机插 水稻最大; 灌浆期和成熟期, 均以手插水稻最大。水 稻穗的比例为抛栽 $>$ 手插 $>$ 机插。栽培方式对水稻产 量影响显著, 抛栽水稻最高, 机插最低, 手插居二 者之间。综合考虑目前农村劳力缺乏的实际情况, 在双季稻主产区可采取水稻抛栽方式和适宜的栽插 方式。机插水稻虽然存在一些问题, 但它是农业发 展的必然趋势, 有待进一步研究完善。

\section{References}

[1] FAO. Statistical Databases. Rome: Food and Agriculture Organization (FAO) of United Nations, 2011

[2] 马殿荣, 陈温福, 王庆祥, 苏芳莉, 周淑清, 陈健. 水稻乳 苗抛栽与其他栽培方式的比较研究. 沈阳农业大学学报, 2003, 34: 336-339

Ma D R, Chen W F, Wang Q Q, Su F L, Zhou S Q, Chen J. Between rice nursling scattering and other planting patterns. $J$
Shenyang Agric Univ, 2003, 34: 336-339 (in Chinese with English abstract)

[3] 何瑞银, 罗汉亚, 李玉同, 汪小函, 张璐. 水稻不同种植方 式的比较试验与评价. 农业工程学报, 2008, 24(1): 167-171 He R Y, Luo H Y, Li Y T, Wang X H, Zhang L. Comparison and analysis of different rice planting methods in China. Trans CSAE, 2008, 24(1): 167-171 (in Chinese with English abstract)

[4] 程建平, 罗锡文, 樊启洲, 张集文, 吴建平, 王在满, 蔵英. 不同种植方式对水稻生育特性和产量的影响. 华中农业大 学学报, 2010, 29: 1-5

Cheng J P, Luo X W, Fan Q Z, Zhang J W, Wu J P, Wang Z M, Zang Y. Influence of different planting methods on growth and development characteristics and yield of rice. J Huazhong Agric Univ, 2010, 29: 1-5 (in Chinese with English abstract)

[5]罗锡文, 谢方平, 欧颖刚, 李佰祥, 郑丁科. 水稻生产不同 栽植方式的比较试验. 农业工程学报, 2004, 20(1): 136-139 Luo X W, Xie F P, Ou Y G, Li B X, Zheng D K. Experimental investigation of different transplanting methods in paddy production. Trans CSAE, 2004, 20(1): 136-139 (in Chinese with English abstract)

[6] 金军, 薛艳凤，于林惠，李伟，徐丹，姜勋良. 水稻不同种 植方式群体质量差异比较. 中国稻米, 2006, (6): 31-33

Jin J, Xue Y F, Yu L H, Li W, Xu D, Qiang X L. Analysis on the different of quality of rice between different planting patterns. China Rice, 2006, (6): 31-33 (in Chinese with English abstract)

[7] 池忠志, 姜心禄, 郑家国. 不同种植方式对水稻产量的影 响及其经济效益比较. 作物杂志, 2008, (2): 73-75

Chi Z Z, Jiang X L, Zheng J G. Comparison of yield and economic effect of rice under different planting patterns. Crops, 2008, (2): 73-75 (in Chinese with English abstract)

[8] 程建平, 吴建平, 王友根, 张集文, 方否. 机插对籼型杂交 水稻生育特性和产量的影响. 中国农机化, 2009, (6): 45-48 Cheng J P, Wu J P, Wang Y G, Zhang J W, Fang L. Growth characteristics and yield formation of rice mechanized transplanting. Chin Agric Mechanization, 2009, (6): 45-48 (in Chinese with English abstract)

[9] 李合松，王学华，吴卫国，唐启源，邓立平，淮万煌. 不同 栽插方式对米粉稻生长发育和产量及稻米品质的影响. 湖 南农业大学学报, 2007, 33: 391-395

Li H S, Wang X H, Wu W G, Tang Q Y, Deng L P, Lin W H. Effects of different transplanting methods on growth development and yield as well as quality of noodle rice. J Hunan Agric Univ, 2007, 33: 391-395 (in Chinese with English abstract)

[10] 郎有忠, 窦永秀, 王美娥, 张祖建, 朱庆森. 水稻生育期对 籽粒产量及品质的影响. 作物学报, 2012, 38: 528-534 Lang Y Z, Dou Y X, Wang M E, Zhang Z J, Zhu Q S. Effects of growth duration on grain yield and quality in rice (Oryza sativa L.). Acta Agron Sin, 2012, 38: 528-534 (in Chinese with English abstract)

[11] 魏祥进, 徐俊锋, 江玲, 王洪俊, 周振玲, 翟虎渠, 万建民. 我国水稻主栽品种抽穗期多样性的遗传分析. 作物学报, 2012, 38: 10-22

Wei X J, Xu J F, Jiang L,Wang H J, Zhou Z L, Zhai H Q, Wan 
J M. Genetic analysis for the diversity of heading date of cultivated rice in China. Acta Agron Sin, 2012, 38: 10-22 (in Chinese with English abstract)

[12] 李秀芬, 贾燕, 黄元才, 藏金䑶. 播栽期对水稻产量和产量构 成因素及生育期的影响. 生态学杂志, 2004, 23(5): 98-100 Li X F, Jia Y, Huang Y C, Zang X. Effects of seeding time on grain yield, yield components and growth duration in different rice varieties. Chin J Ecol, 2004, 23(5): 98-100 (in Chinese with English abstract)

[13] 黄雅丽, 陈刚, 陈楠, 黄义德. 播期和密度对麦茬中粳稻皖 稻 68 生育期和产量形成的影响. 中国农学通报，2009, 25(15): 95-99

Huang Y L, Chen G, Chen N, Huang Y D. The effect of sowing date and density of rice stubble in Wandao 68 reproductive period and yield formation. Chin Agric Sci Bull, 2009, 25(15): 95-99 (in Chinese with English abstract)

[14] 李杰, 张洪程, 董洋阳, 倪晓诚, 杨波, 龚金龙, 常勇, 戴 其根, 霍中洋, 许轫, 魏海燕. 不同生态区栽培方式对水稻 产量、生育期及温光利用的影响. 中国农业科学, 2011, 44: 2661-2672

Li J, Zhang H C, Dong Y Y, Ni X C, Yang B, Gong J L, Chang Y, Dai Q G, Huo Z Y, Xu K, Wei H Y. Effects of cultivation methods on yield, growth stage and utilization of temperature and illumination of rice in different ecological regions. Sci Agric Sin, 2011, 44: 2661-2672 (in Chinese with English abstract)

[15] 魏金连, 潘晓华. 夜间温度升高对早稻生长发育及产量的 影响. 江西农业大学学报, 2008, 30: 427-432

Wei J L, Pan X H. Effects of night temperature increase on growth and yield of early season rice. Acta Agric Univ
Jiangxiensis, 2008, 30: 427-432 (in Chinese with English abstract)

[16] 吴文革, 张洪程, 钱银飞, 陈烨, 徐军, 吴桂成, 翟超群, 霍中洋, 戴其根. 超级杂交中籼水稻物质生产特性分析. 中国水稻科学, 2007, 21:287-293

Wu W G, Zhang H C, Qian Y F, Cheng Y, Xu J, Wu G C, Zhai C Q, Huo Z Y, Dai Q G. Analysis on dry matter production characteristics of middle-season indica super hybrid rice. Chin J Rice Sci, 2007, 21: 287-293 (in Chinese with English abstract)

[17] 李杰, 张洪程, 常勇, 龚金龙, 郭振华, 戴其根, 霍中洋, 许轫, 魏海燕, 高辉. 不同种植方式水稻高产栽培条件下 的光合物质生产特征研究. 作物学报, 2011, 37: 1235-1248 Li J, Zhang H C, Chang Y, Gong J L, Guo Z H, Dai Q G, Huo Z Y, Xu K, Wei H Y, Gao H. Characteristics of photosynthesis and matter production of rice with different planting methods under high-yielding cultivation condition. Acta Agron Sin, 2011, 37: 1235-1248 (in Chinese with English abstract)

[18] 马殿荣, 陈温福, 苏英山, 李否金鍂, 高峰. 水稻乳苗抛栽与 其它栽培方式干物质生产特性的比较研究. 辽宁农业科学, 2004, (5): 6-9

Ma D R, Chen W F, Su Y S, Li L X, Gao F. Comparison of dry matter accumulation between rice nursing seedlings scattering and other planting patterns. Liaoning Agric Sci, 2004, (5): 6-9 (in Chinese with English abstract)

[19] 刘军, 余铁桥. 大穗型水稻超高产产量形成特点及物质生 产分析. 湖南农业大学学报, 1998, 24(1): 1-6

Liu J, Yu T Q. Analysis of the formation of super-high yield of big panicle rice and its dry matter production. J Hunan Agric Univ, 1998, 24(1): 1-6 (in Chinese with English abstract) 